\title{
AS "FRONTEIRAS" DA REGIÃO METROPOLITANA DO RIO DE JANEIRO: MUDANÇAS TERRITORIAIS E AJUSTES NO CIRCUITO ECONÔMICO- PRODUTIVO
}

\author{
Leandro Dias de OLIVEIRA \\ PPGGEO , Universidade Federal Rural do Rio de Janeiro (UFRRJ / Brasil) \\ Idiasufrrj@gmail.com
}

\begin{abstract}
Resumo
O objetivo deste artigo é fazer uma breve revisão analítica da expansão econômica da Região Metropolitana do Rio de Janeiro. Após o momento de expansão, no início do século XXI, com a implementação de novas empresas dos ramos industrial e logístico, num processo de consolidação econômica de suas "fronteiras", a Região Metropolitana do Rio de Janeiro vive um verdadeiro desmoronamento político, econômico e social mediante a grave crise que atinge o Brasil nos últimos anos. Fruto de dez anos de investigação e amparado na pesquisa de pós-doutoramento, realizado na Universidade do Estado do Rio de Janeiro, no âmbito do Programa de Pós-Graduação em Políticas Públicas e Formação Humana (PPFH-UERJ), a proposta é fazer um balanço teórico do modelo e apresentar novos desafios de pesquisa.
\end{abstract}

Palavras chave: Região Metropolitana do Rio de Janeiro - Desenvolvimento Econômico Crise.

\begin{abstract}
The objective of this article is to make a brief analytical review of the economic expansion of the Metropolitan Region of Rio de Janeiro. After the moment of expansion, in the beginning of the 21st century, with implementation of new enterprises in industrial and logistical the economic consolidation of its "Frontiers", the Metropolitan Region of Rio de Janeiro is experiencing a real political, economic and social collapse due to the serious crisis that has hit Brazil in recent years. As a result of ten years of research and supported by postdoctoral research, conducted at the Universidade do Estado do Rio de Janeiro, under the Programa de Pós-Graduação em Políticas Públicas e Formação Humana (PPFH-UERJ), the proposal is to make a theoretical balance of the model and present new research challenges.
\end{abstract}

Keywords: Metropolitan Region of Rio de Janeiro - Economic Development - Crisis.

\section{Introdução}

Nas últimas duas décadas, o estado do Rio de Janeiro assistiu à expansão da metrópole por meio de novas centralidades econômicas, industriais e logísticas situadas em suas "fronteiras", que têm se caracterizado pela expansão urbana, política, econômica, cultural e ambiental da própria 
metrópole. A implantação de indústrias, de empreendimentos logísticos e condominiais permitiu alentar a concretização de um circuito econômico-produtivo, no qual nas bordas da metrópole novas economias de aglomeração urbana se consolidam, reconstituindo os novos empreendimentos produtivos como centralidades urbanas e requalificando a indústria.

Tais transformações, especialmente no que se refere ao Oeste Metropolitano Fluminense formado pelas cidades de Seropédica, Itaguaí, Paracambi, Japeri e Queimados -, têm sido foco de nossas análises na última década (Ver: OLIVEIRA e ROCHA, 2012 e 2014; OLIVEIRA, 2015, 2016 e 2017). Mas, mediante a crise de graves proporções que assolou o Brasil nos últimos anos, agravada pela deposição da então presidente Dilma Rousseff em 2016, o Rio de Janeiro tem vivido uma verdadeira "atmosfera de crise", com a desconstrução das bases produtivas emergentes e constante piora dos índices econômicos e sociais em seu território.

Este trabalho se divide em três principais núcleos de análise: [1] uma breve revisão da expansão econômica do Rio de Janeiro, como escopo especialmente na Região Metropolitana Fluminense; [2] os "marcos teóricos" consolidados na pesquisa efetivada acerca da dinamização produtivo-logística do estado do Rio de Janeiro e a constituição de uma verdadeira "atmosfera de crise"; e, por fim, [3] os novos caminhos e desafios de investigação em meio ao desmoronamento e as novas oportunidades do recorte espacial aqui consolidado.

\section{A expansão econômica do Rio de Janeiro: um olhar a partir do Oeste Metropolitano Fluminense}

Durante décadas, o estado do Rio de Janeiro esteve marcado pela evasão de fábricas, desmobilização de ramos estratégicos e migração de sedes empresariais para outros estados (Floriano OLIVEIRA, 2008; SILVA, 2012). Todavia, nos últimos vinte anos, o território fluminense se tornou um polo atrativo de investimentos. Ou seja, houve o aparecimento de novos investimentos e ou incremento de antigas bases produtivas, que compreendem a instalação do Complexo Petroquímico do Rio de Janeiro - COMPERJ, a ampliação do complexo portuário de Itaguaí e a implementação do Arco Rodoviário Metropolitano do Rio de Janeiro, ligando bordas metropolitanas para além da capital. Evidentemente, este ciclo virtuoso da economia fluminense [e brasileira] vive o seu reverso, de maneira que o estado do Rio de Janeiro assiste o estacionamento de suas obras, a fuga de capitais, a retração produtiva e pessimismo em curto prazo acerca dos rebatimentos da crise de largo espectro econômico nacional e internacional.

Não há dúvidas que tais investimentos modificaram a paisagem geoeconômica do estado do Rio de Janeiro. Se tal expansão econômica tem implicado na redinamização da própria Região Metropolitana (OLIVEIRA, 2006 e 2008; PAGANOTO, BECKER, 2012; SILVA, 2012; SOBRAL, 2013), a Baixada Fluminense também foi impactada pelo espraiamento dos serviços em suas diversas formas (hotéis, shoppings, supermercados etc.) (SIMÕES, 2007; OLIVEIRA \& RODRIGUES, 2009; ROCHA, 2014 e 2015; OLIVEIRA, 2014), por meio da constituição de áreas revitalizadas e manutenção dos problemas sociais históricos. 
Neste item, as cidades de Itaguaí, Japeri, Paracambi, Queimados e Seropédica - observar, na Figura 1, que tais cidades formam a parte oeste da Região Metropolitana - preconizaram um verdadeiro processo de industrialização, ainda que com características bastante peculiares, ultrapassando-se os modelos de grandes plantas fabris e vilas operário-industriais e adotando-se sistemas de volatilização, subcontratação e terceirização de funcionários. Esta industrialização extemporânea implicou na ideologização do processo de implantação das indústrias como signo de progresso combinada com uma mão-de-obra com diferentes níveis de qualificação. A borda da área metropolitana do Rio de Janeiro redinamizou-se como área de expansão, influência e polo de propagação da própria metrópole.

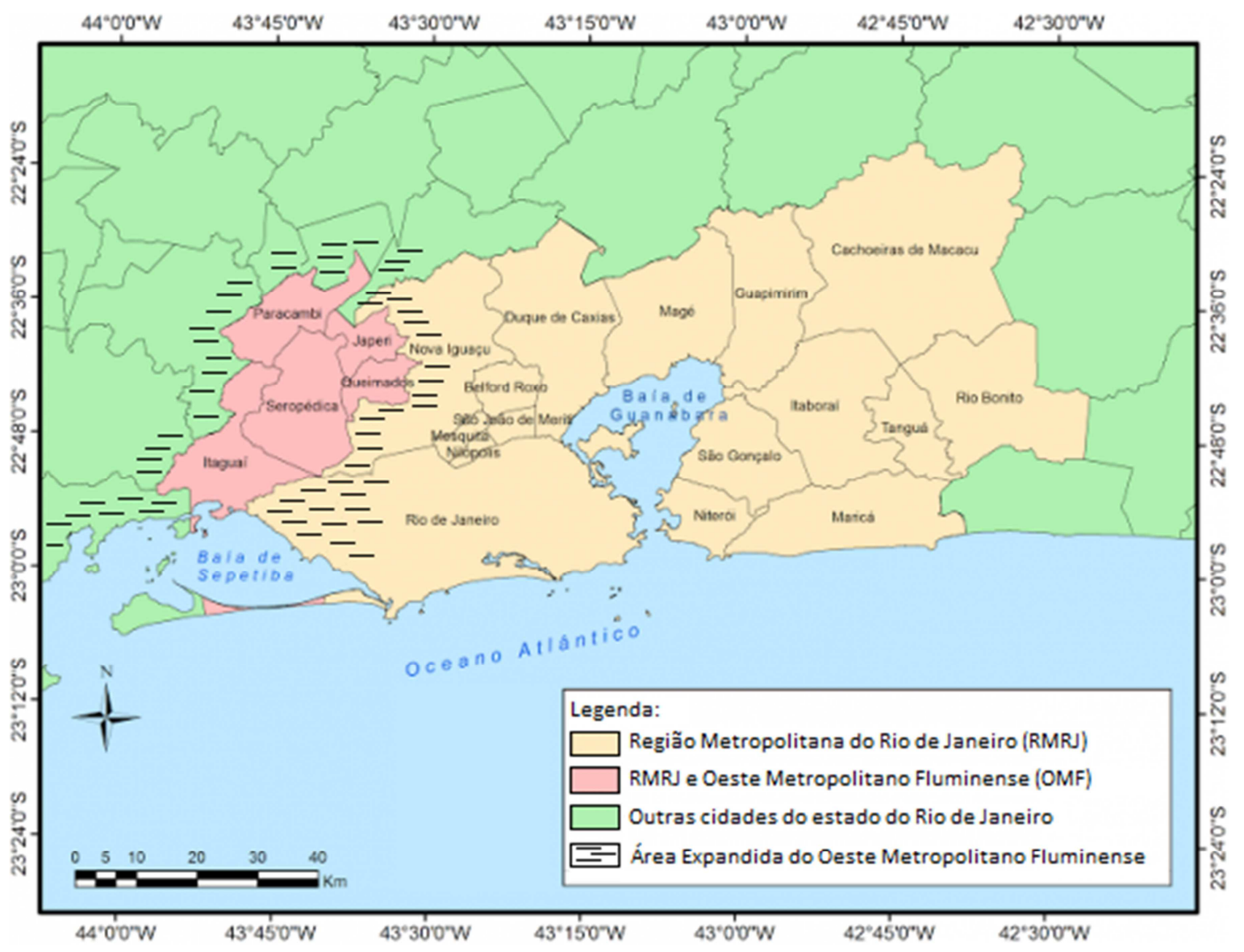

Figura 1: Oeste Metropolitano Fluminense Fonte: Organização: Prof. Dr. Leandro Dias de Oliveira e Prof. Dr. Andrews José de Lucena [DGG/PPGGEO/UFRRJ]. Novembro / 2015 [Adaptado]

Neste sentido, reforça-se a contiguidade da parte oeste da região metropolitana com a Região do Médio Vale Paraíba Fluminense, seja pelo entroncamento logístico, seja pela potencialidade de contatos com a economia regional baseada no ramo metal-siderúrgico-automobilístico baseada no eixo Volta Redonda - Resende. Da mesma maneira, consolida-se um verdadeiro eixo produtivo com o Leste Metropolitano, onde a constituição de Itaboraí como polo petrolífero envolveu a proposição de 
um contato profícuo com a Região Norte Fluminense, cuja economia petrolífera permanece como motor do desenvolvimento e praticamente envolve todas as cidades do Norte-Nordeste do estado. A REDUC (Refinaria Duque de Caxias, na cidade homônima) completa o encadeamento energéticopetrolífero do estado do Rio de Janeiro (PESSANHA, 2015). Ainda é importante asseverar que Itaguaí é a porta de entrada da "Região da Costa Verde", que vive grande expansão de oferta de moradias em condomínios residenciais de classe média e alta.

A borda metropolitana torna-se responsável por oferecer na realidade do Rio de Janeiro "convecções econômicas", por meio de redes convectivas de troca de mercadorias e da consolidação de uma verdadeira engrenagem da oferta de empregos, construção de condomínios, meios de transporte, na ampliação das vagas em escolas e universidades, acordos e trocas políticas, ajustes ambientais e reestruturação urbano-regional (OLIVEIRA, 2015). Assim, a criação dos Condomínios Industriais I, II e III no bairro Marajoara (distrito de Engenheiro Pedreira), em Japeri, em 2005, junto às áreas da APA (Área de Proteção Ambiental) do Rio Guandu, com inúmeras empresas de diferentes portes, com destaque para a unidade fabril da Granado, a INCOPRE [pré-fabricados de concreto], a Embelmar (empresa de envazamento da EMBELLEZE) e a Poly Rio Polimeros Ltda; implantação dois condomínios Industriais em Paracambi, em 2002, às margens da Estrada RJ-127, com mais de dez indústrias em funcionamento, como a Lansa Ferro e Aço e Botafogo Lar e Lazer; a consolidação do Distrito Industrial de Queimados, instituído em 1976, nas margens da Rodovia Presidente Dutra e próxima ao Rio Guandu, com 23 empresas ativas, como a Arfrio, Citycol, Tangará Foods/Sanes, Quartzolit, etc.; a formação em Itaguaí de uma verdadeira "capitania industrial", com especial destaque para a llha da Madeira e a efetivação do contíguo industrial Itaguaí-Santa Cruz [Rio de Janeiro], com destaque para a Ternium Companhia Siderúrgica do Atlântico (antiga TKCSA), a Gerdau, a Usiminas, etc. combinados com a expansão do Porto de Itaguaí e a fundação do Porto Sudeste; e, por fim, ao acolhimento recente em Seropédica, especialmente devido à sua posição logística, de empresas como a Eletrobolt, a alimentícia Panco, a Procter \& Gamble e de condomínios logísticos, como o Golgi Seropédica, na RJ-125, e VBI LOG Seropédica, próximo à Rodovia Presidente Dutra expressam a dimensão dos investimentos realizados nesta região, polo atrativo para o modelo de desenvolvimento empreendido desde a virada de século.

É lição básica de geografia econômica que todo e qualquer empreendimento causa impacto de diferentes forças escalares. De um lado, seja por meio de economias de aglomeração - noção que implica na atração econômica e transbordamento de ações oriundas pela instalação de aportes na cidade -, resultado na emersão de novos aportes de setores secundários e terciários, como a construção civil e as demandas por serviços diversos; de outro, ainda que as empresas tenham baixos índices de ofertas de empregos e admitam funcionários com diferentes níveis de qualificação [e não somente de conhecimentos elementares, como se tornou comum argumentar], há evidente ampliação do número de habitantes locais, em busca de novas oportunidades. O aumento populacional desta sub-região pode ser verificado comprando-se as tabelas 1 e 2 . 
Nota-se facilmente que o crescimento populacional das cidades que compõem o Oeste Metropolitano Fluminense - Itaguaí, Japeri, Paracambi, Queimados e Seropédica - é bastante significante. O percentual de crescimento de todas as cidades entre o ano 2000 e a estimativa atual do IBGE é maior que a da cidade do Rio de Janeiro e de todo o estado no mesmo período. Assim como nas cidades da Região das Baixadas Litorâneas e do Médio Vale Paraíba Fluminense, o Oeste Metropolitano Fluminense impulsionou o crescimento populacional do estado do Rio de Janeiro. São novos moradores, enfrentando novas questões políticas, econômicas, sociais e ambientais.

Tabela 1- Crescimento Populacional - Cidades do Oeste Metropolitano Fluminense

\begin{tabular}{l|c|c|c|c}
\hline \multicolumn{1}{c|}{ Cidades } & $\mathbf{2 0 0 0}$ & $\mathbf{2 0 1 0}$ & $\mathbf{2 0 1 8}$ & $\begin{array}{c}\text { Percentual de Crescimento } \\
\text { [2000-2018] }\end{array}$ \\
\hline Itaguaí & 82.003 & 109.091 & 125.913 & $53,55 \%$ \\
\hline Japeri & 83.278 & 95.492 & 103.960 & $24,83 \%$ \\
\hline Paracambi & 40.475 & 47.124 & 51.815 & $28,02 \%$ \\
\hline Queimados & 121.993 & 137.962 & 149.265 & $22,36 \%$ \\
\hline Seropédica & 65.260 & 78.186 & 86.743 & $32,92 \%$ \\
\hline Oeste Metropolitano Fluminense & $\mathbf{3 9 3 . 0 0 9}$ & $\mathbf{4 6 7 . 8 5 5}$ & $\mathbf{5 1 7 . 6 9 6}$ & $\mathbf{3 1 , 7 3 \%}$ \\
\hline
\end{tabular}

Organização: Leandro Dias de Oliveira [Outubro, 2018], com dados do IBGE (Censo 2000, Censo 2010 e Estimativa 2018)

Tabela 2: Crescimento Populacional - Cidade e Estado do Rio de Janeiro

\begin{tabular}{l|c|c|c|c}
\hline & $\mathbf{2 0 0 0}$ & $\mathbf{2 0 1 0}$ & $\mathbf{2 0 1 8}$ & $\begin{array}{c}\text { Percentual de Crescimento } \\
\text { [2000-2018] }\end{array}$ \\
\hline Cidade do Rio de Janeiro & 5.857 .904 & 6.320 .446 & 6.688 .927 & $14,19 \%$ \\
\hline Estado do Rio de Janeiro & 14.391 .282 & 15.989 .929 & 17.159 .960 & $19,24 \%$ \\
\hline
\end{tabular}

Organização: Leandro Dias de Oliveira [Outubro, 2018], com dados do IBGE (Censo 2000, Censo 2010 e Estimativa 2018)

\section{Marcos teóricos da dinamização metropolitana do Rio de Janeiro: Um esforço de análise}

As mudanças ocorridas na Região Metropolitana do Rio de Janeiro, constituídas a partir de novos investimentos produtivo-logísticos - basicamente, empreendimentos fabris, galpões e silos de estocagem e trânsito de mercadorias, estruturas rodoviárias e portuárias de transportes de carga, etc. - não somente reverberam a ideologia do desenvolvimento, mas suas adaptações contemporâneas: 
desenvolvimento local, regional, sustentável, integrado, bem como ocorrem com seletivas adaptações do modelo flexível de produção.

Assim, é possível traçar alguns importantes marcos teóricos, sob o prisma da Geografia Econômica e da Indústria e a partir da experiência da análise metodológica da geoeconomia das fronteiras da Região Metropolitana do Rio de Janeiro:

[1] Ocorreu a reabilitação da fábrica como esperança de desenvolvimento e criação de uma espécie de "acumulação flexível à brasileira";

Ciente que o fordismo não completou o ciclo evolutivo em terras brasileiras, torna-se possível alentar que houve a emergência de uma espécie de "acumulação flexível à brasileira", adequando o arcaico e o moderno, a vigilância e a multifunção, o controle e o distanciamento urbano, que em conjunto inscrevem no trabalhador as características mais duras de ambos os regimes de acumulação. Assim, à revelia dos péssimos indicadores sociais destas cidades, a chegada de novos empreendimentos redinamizou a crença no defasado modelo de desenvolvimento em moldes "fordistas", fazendo com que cada indústria que anuncie sua instalação nestas cidades seja saudada como um grande triunfo das prefeituras.

[2] Houve a consolidação da ideologia do desenvolvimento sustentável como opção produtiva;

Junto ao atual processo de industrialização em curso emerge o modelo de adequação sociedade-natureza em moldes destacadamente econômicos intitulado desenvolvimento sustentável. Trata-se de um modelo eminentemente produtivo, que propugna a utilização mais racional da natureza, a absorção de técnicas de filtragem e despoluição e mecanismos de compensação ambiental. Assim, bastou que cidades outrora com características rurais iniciassem um movimento de industrialização para que a questão ambiental emergisse nas políticas públicas das Prefeituras Municipais e nos setores de marketing das empresas recém-chegadas; ou seja, no exato momento que rompem progressivamente o estatuto da ruralidade, a "proteção do meio ambiente" se tornou um significativo alvo político.

[3] O álibi logístico se tornou um trunfo territorial do modelo "foot-loose" do desenvolvimento industrial;

O advento do Arco Rodoviário Metropolitano, uma rodovia que margeia a capital estadual e aproxima o leste do oeste da região metropolitana, é o símbolo maior de uma verdadeira revolução no universo dos transportes de carga fluminense: junto às demais estradas existentes - Rodovia 
Presidente Dutra (BR-116) e Rodovia Rio-Santos (BR-101), além da RJ-099, conhecida como Reta de Piranema, da Rodovia Ary Schiavo (RJ-125), da RJ-127 (acesso a Paracambi), entre outras -, linhas férreas da MRV e complexo portuário de Itaguaí, a parte oeste se tornou símbolo de mobilidade, fluidez e desenraizamentos, num território sem barreiras, marcas, signos, viscosidades e espessuras da sociedade local. A logística é o capital se realizando em velocidade para além da vida urbana.

Mesmo com o desmoronamento do modelo "aceleração do crescimento", há de fato a consolidação de tais áreas como novos polos produtivos. O desmantelamento do modelo de desenvolvimento nacional, a contração do mercado imobiliário, o arrefecimento dos investimentos industriais, a subutilização de alguns empreendimentos e o próprio alastramento da crise política, econômica e social que o Brasil vive implicaram numa abordagem geral bastante pessimista sobre o crescimento produtivo do estado e do próprio país.

Assim, é importante destacar: [1] As cidades situadas nas fronteiras da região metropolitana se consolidaram, ainda que com a crise atual, como pontos de reverberação metropolitana; [2] $O$ desinvestimento e dissolução do modelo desacelerou a consolidação econômica destes espaços, mas os objetos criados permanecem como novas oportunidades industrial-mercadológicas, em qualquer regime de acumulação que se proponha e que se constitua futuramente; [3] A desestruturação em curso apresenta trágica repercussão social nas bordas metropolitanas do Rio de Janeiro e se torna um profundo abalo no próprio sentimento de esperança. Se a população local já enxergava com desconfiança os empreendimentos instalados no território, a crise revelou que os investimentos sonhados - postos de saúde, escolas, praças públicas, asfaltamento, saneamento básico, coleta de lixo regular; mobilidade espacial, segurança - se tornaram mais distantes nesta verdadeira "atmosfera de crise".

\section{Para não concluir: para além do Oeste Metropolitano Fluminense}

Em tempos de crise e desmoronamento produtivo do recorte espacial analisado, os desafios analíticos permanecem. Metodologicamente, nossos esforços sempre partiram de estudos já considerados clássicos no pensamento geográfico contemporâneo, como "Condição Pós-Moderna: Uma Pesquisa sobre as Origens da Mudança Cultural" (1989) e "Justice, Nature and the Geography of Difference" (1996), de autoria de David Harvey, atentando às flexibilizações produtivas em curso, ainda que para além da dicotomização simples entre modelos fechados de "fordimo" e "acumulação flexível"; as obras "Geografias Pós-Modernas: A Reafirmação do Espaço na Teoria Social Crítica" (1993) e "Postmetropolis: Critical Studies of Cities and Regions" (2000), de Edward Soja, permitiram analisar as "edge cities", nas quais a suburbanização e o crescimento das periferias colocam em questão a centralidade urbana desta verdadeira "galáxia metropolitana" contemporânea, permitindose refletir acerca das frentes produtivo-logísticas destas áreas que proporcionam a expansão da metrópole de variadas maneiras e da formação de um cordão turístico pós-metropolitano. 
Além destes, trabalhos como "Technopolis: High-Tecnology Industry and Regional Development in Southern California" (1993) e "The Capitalist Imperative: Territory, Technology and Industrial Growth" (1989), o primeiro de Allen Scott e o outro de Michael Storper e Richard Walken, fundamentam a interpretação da retomada do desenvolvimento regional e constituição das aglomerações locais flexíveis. Por fim, textos como "Desenvolvimento Desigual: Natureza, Capital e a Produção do Espaço" (1988), de Neil Smith, e "O fim do capitalismo como o conhecemos" (2010), de Elmar Altvater, são norteadores das reflexões acerca do modelo de desenvolvimento sustentável e da readequação sociedade-natureza do tempo presente. São todas obras norteadoras que alicerçaram nossos estudos e permitirão caminhar por novos horizontes de pesquisa e se aproximar de temáticas e questões teóricas mais contemporâneas.

Assim, para além da borda metropolitana, o que assistimos no entorno regional é a emersão de um processo de "condominização" e "turistificação" nos espaços contíguos-imediatos. Mangaratiba, por exemplo, cidade vizinha à Itaguaí e porta de entrada para a região turística da Costa Verde, vive um processo de "resortificação do espaço", com a corroboração de atividades de turismo e recreação para o cidadão metropolitano. Assim, novos espaços no interior do estado alimentam um novo modo de consumir o tempo livre na mesma medida que se assistem a expansão da malha urbana para além da metrópole. $O$ avanço da população metropolitana para áreas litorâneas e serranas do estado a fim de encontrar espaços de revigoramento, mesmo diante da construção de um complexo portuário bem próximo à região e degradação da Baía de Sepetiba, é consolidado com empreendimentos com bandeiras internacionais na área de hospedagem (DINIZSILVA, 2018). Tais mudanças territoriais significam importantes ajustes no circuito econômicoprodutivo do Rio de Janeiro.

Assim como a Costa Verde, a Região do Vale do Café, contígua ao Oeste Metropolitano, é a denominação turística para o conjunto de quinze cidades - Vassouras, Valença, Rio das Flores, Piraí, Engenheiro Paulo de Frontin, Paty do Alferes, Paracambi ${ }^{1}$, Miguel Pereira, Mendes, Barra do Piraí, Pinheiral, Barra Mansa, Paraíba do Sul, Volta Redonda e Resende - que juntos chegaram a produzir, na década de [18]60,75\% do café consumido no mundo, fazendo do Brasil o líder mundial na produção e exportação deste produto. Está em curso a redinamização da visitação turística às cerca de trinta fazendas históricas do café preservadas em sua arquitetura, que remetem ao tempo em que os barões ostentavam poder e riqueza.

Também contígua e em constante convecção econômica com a Região Metropolitana, a Região Serrana tem consolidado novas frentes turísticas, como o caso da Rota Turística e Cervejeira do Rio de Janeiro, que abrange as cidades de Petrópolis, Teresópolis, Nova Friburgo, Santa Maria Madalena, Guapimirim e Cachoeiras do Macacu, envolvendo atrações como as intituladas "beer experiences" nas grandes cervejarias, degustações harmonizadas e visitas às microcervejarias combinadas com os próprios atrativos turísticos destas cidades. Segundo a ACCERJ (Associação Turística das Cervejarias e Cervejeiros do Estado do Rio de Janeiro), fazem parta da Rota Cervejeira

\footnotetext{
${ }^{1}$ A regionalização turística do Rio de Janeiro possui sobreposições com a regionalização político-administrativa. Paracambi, neste caso, pertence à Região do Vale do Café, pois possui uma fazenda histórica e corresponde à porta de entrada da região.
} 
na cidade de Petrópolis a Cervejaria Bohemia [maior centro de experiência cervejeira do país], a Cervejaria Cidade Imperial [fábrica da família Orleans e Bragança e que possui um beer tour], o Grupo Petrópolis, a Cervejaria Real, além da Cervejaria Buda Beer (esta possui um brewpub), a Cervejaria Duzé, a Cervejaria da Corte, a Cervejaria Cazzera e a Imperatriz Beer, todas de pequeno e médio porte e que produzem cervejas de tipos e ascendências variadas. Com um calendário já consolidado de atrações, Petrópolis, a Cidade Imperial, promove anualmente a Bauernfest no Palácio de Cristal, com uma série de atrações dedicadas à produção e comercialização de cerveja.

Conforme é perceptível, estudar a realidade fluminense e a economia regional em áreas contíguas à região metropolitana é um exercício analítico fundamental para pensar uma política de desenvolvimento mais integrado e harmônico do Rio de Janeiro, com a superação da crônica hipertrofia econômica do núcleo metropolitano. Pensa-se assim nas potencialidades do desenvolvimento local, com melhor distribuição dos recursos e divisão mais igualitária dos dividendos que dê contributos para uma vida melhor para todos. Outrossim, consolida-se o processo de "exopolização" - entendido aqui como crescimento para além do núcleo metropolitano -, que ocasiona a consolidação de um cinturão de amortecimento por intermédio de um verdadeiro "escapismo" dos ritmos metropolitanos.

São questões de fundamental importância para se compreender a economia da fronteira metropolitana do Rio de Janeiro no tempo presente. Pensa-se assim nas potencialidades do desenvolvimento local, com melhor distribuição dos recursos e divisão mais igualitária dos dividendos que dê contributos para uma vida melhor para todos, e que desta maneira não se efetive um processo de desenvolvimento urbano-econômico que seja concentrador, excludente e que apenas repita os erros históricos, mas antes que dê contributos para uma vida melhor para todos.

\section{Agradecimentos}

Estas reflexões estão vinculadas ao Grupo de Pesquisa "Reestruturação Econômico-Espacial Contemporânea" [DGG-PPGGEO-UFRRJ] e se baseiam nos resultados finais do projeto de pesquisa "O Processo de Reestruturação Territorial-Produtiva do Oeste Metropolitano Fluminense", desenvolvido com o apoio da Fundação Carlos Chagas Filho de Amparo à Pesquisa do Estado do Rio de Janeiro - FAPERJ (Auxílio Instalação / 2012 e bolsas de iniciação científica), do CNPq Conselho Nacional de Desenvolvimento Científico e Tecnológico e da CAPES - Coordenação de Aperfeiçoamento de Pessoal de Nível Superior, por meio de bolsas de iniciação científica (PIBIC), iniciação à docência (PIBID) e de mestrado. Agradecemos, assim, à FAPERJ, ao CNPq e à CAPES pelo apoio imprescindível à realização destas investigações.

Este estudo também é integrante do projeto de cooperação internacional, no campo da geografia, entre a Universidade Federal Rural do Rio de Janeiro e a Universidade do Porto, intitulado "Reestruturação Espacial e Desenvolvimento Regional: Um Estudo Comparativo entre a Região Norte de Portugal e o Estado do Rio de Janeiro", do qual o autor é coordenador juntamente com a Prof. 
Dr. a Maria Helena Mesquita Pina, da Universidade do Porto, a quem agradecemos pelo importantíssimo diálogo no cumprimento das agendas de pesquisa. Por fim, este trabalho também é fruto dos esforços no âmbito do NuPEE - Núcleo de Pesquisa Espaço e Economia, coordenado pelo Prof. Dr. Floriano José Godinho de Oliveira (UERJ), supervisor de nosso estágio pós-doutoral no Programa de Pós-Graduação em Políticas Públicas e Formação Humana da Universidade do Estado do Rio de Janeiro (PPFH-UERJ), por intermédio do desenvolvimento do projeto "Estado, Políticas de Gestão e Território: Um estudo sobre o Oeste Metropolitano do Rio de Janeiro", a quem agradecemos pelos ensinamentos sempre oportunos.

\section{Bibliografia}

ALTVATER, E (2010). O fim do capitalismo como o conhecemos. Rio de Janeiro: Civilização Brasileira.

DINIZ-SILVA, R. C. (2018). A produção do espaço de lazer: Um estudo sobre "turistificação" e "resortificação" a partir do Portobello Resort \& Safári (Mangaratiba-RJ). Seropédica (RJ): Dissertação de Mestrado em Geografia, PPGGEO - Programa de Pós-Graduação em Geografia, UFRRJ - Universidade Federal Rural do Rio de Janeiro.

HARVEY, D. (1989). Condição Pós-Moderna: uma pesquisa sobre as origens da mudança cultural. São Paulo: Loyola.

HARVEY, D. (1996). Justice, Nature and the Geography of Difference. Oxford: Blackwell Publishing.

OLIVEIRA, A.; RODRIGUES, A. O. (2009). Industrialização na periferia da região metropolitana do Rio de Janeiro: novos paradigmas para velhos problemas. Semestre Económico, v. 12, n. 24, p. 127-143. Disponível

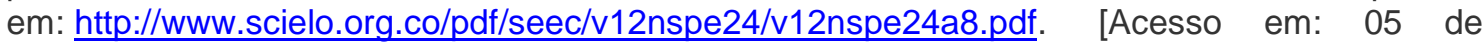
dezembro de 2015].

OLIVEIRA, F. J. G. de (2006). Mudanças no espaço metropolitano: novas centralidades e dinâmicas espaciais na metrópole. In: F. J. G. de OLIVEIRA; C. A. S; D. G. FREIRE. Guichard. Metrópole: governo, sociedade e território (pp. 80-97). Rio de Janeiro: DP\&A.

OLIVEIRA, F. J. G. de (2008). Reestruturação produtiva, território e poder no Rio de Janeiro. Rio de Janeiro: Editora Garamond / Faperj.

OLIVEIRA, L. D. de (2017). A construção da Cidade Sustentável: Um estudo de caso sobre Seropédica (Rio de Janeiro, Brasil). In: H. Pina; P. Remoaldo; M. da C. Ramos (Orgs.). Grandes Problemáticas do Espaço Europeu - Sociedade, Economia e Património num Contexto de Maior Coesão Territorial (pp. 301-311). Porto: Fundação Universidade do Porto Faculdade de Letras da Universidade do Porto.

OLIVEIRA, L. D. de (2014). Uma Nova Geografia da Baixada Fluminense. Resenha do livro de MAGALHÃES, A. L.; ROCHA, A. S. da; SANTANA, M. C. de; SANTOS FILHO, Sidney Cardoso. Alma(naque) da Baixada! [Duque de Caxias - RJ, Editora APPH-CLIO, 2013, 104 p.] Recôncavo: Revista de História da UNIABEU, V. 4, N. 7, Julho-dezembro de 2014. Disponível em: www.uniabeu.edu.br/publica/index.php/reconcavo/article/.../pdf 46. Acesso em: 10 de setembro de 2018.

OLIVEIRA, L. D. de (2016). Seropédica Sustentável: Transformações ecológico-econômico-espaciais recentes em um lacônico julgamento. Recôncavo: Revista de História da UNIABEU, v. 6, p. 87101.

OLIVEIRA, L. D. de (2015). A emersão da região logístico-industrial do Extremo Oeste Metropolitano fluminense: reflexões sobre o processo contemporâneo de reestruturação territorial-produtiva. Espaço e Economia: Revista Brasileira de Geografia Econômica, v. IV, p. 1-30. 
OLIVEIRA, L. D. de; ROCHA, A. S. da (2012). As Novas Dinâmicas Produtivas em curso na Baixada Fluminense: Breves apontamentos sobre uma nova geografia da indústria. Revista Pilares da História, v. Ano 11, p. 7-13.

OLIVEIRA, L. D. de; ROCHA, A. S. da (2014). Neodesenvolvimentismo e reestruturação produtiva: O processo de reordenamento territorial no Oeste Metropolitano Fluminense (Rio de Janeiro, Brasil). In: H. Pina; P. Remoaldo; M. da C. Ramos; H. Marques. (Orgs.). Grandes Problemáticas do Espaço Europeu: Diversidade Territorial e Oportunidades de Desenvolvimento num Cenário de Crise (pp. 126-142). Porto: Fundação Universidade do Porto - Faculdade de Letras da Universidade do Porto.

PAGANOTO, F.; BECKER, O. M. (2012). A emergência de novas centralidades na periferia da Região Metropolitana do Rio de Janeiro e a reorganização dos deslocamentos espaciais da população. Anais do XVIII Encontro Nacional de Estudos Populacionais, ABEP. Águas de Lindóia/SP.

Disponível em: http://www.abep.nepo.unicamp.br/xviii/anais/files/POSTER[116]ABEP2012.pdf. Acesso em: 10 de novembro de 2015.

PESSANHA, R. M. (2015). A ampliação da fronteira de exploração petrolífera no Brasil é parte da geopolítica da energia: oportunidades e riscos de inserção global em meio às novas territorialidades regionais e ao desafio da abundância na economia dos royalties no Estado do Rio de Janeiro. Espaço e Economia: Revista Brasileira de Geografia Econômica, Ano 3, n.ㅇ 6, Janeiro / Junho de 2015. Disponível em: http://espacoeconomia.revues.org/1511. [Acesso em: 10 de dezembro de 2015].

ROCHA, A. S. da (2014). As representações ideais de um território: Dinâmica econômica e política, agentes e a produção de novos sentidos na apropriação territorial da Baixada Fluminense pós 1990. Rio de Janeiro: Tese de Doutorado em Geografia, PPGG - Programa de Pós-Graduação em Geografia, UFRJ - Universidade Federal do Rio de Janeiro.

ROCHA, A. S. da (2015). Os efeitos da reestruturação econômica metropolitana na Baixada Fluminense: Apontamentos sobre o "novo" mercado imobiliário da região. Espaço e Economia: Revista Brasileira de Geografia Econômica, Ano 3, n.ำ 6, Janeiro / Junho de 2015. Disponível em: http://espacoeconomia.revues.org/1677. [Acesso em: 10 de dezembro de 2015].

SCOTT, A. J. (1993) Technopolis: High-Tecnology Industry and Reginonal Development in Southern California. Berkeley: Un. of California Press, 1993.

SILVA, R. D. da (2012). Indústria e Desenvolvimento Regional no Rio de Janeiro (1990-2008). Rio de Janeiro: Editora FGV [Faperj].

SIMÕES, Manoel Ricardo (2007). A cidade Estilhaçada - reestruturação econômica e emancipações municipais na Baixada Fluminense. Mesquita: Entorno.

SMITH, N. (1988).Desenvolvimento Desigual: natureza, capital e a produção do espaço. Rio de Janeiro: Bertrand Brasil.

SOBRAL, B. L. B. (2013). Metrópole do Rio e projeto nacional: Uma estratégia de desenvolvimento a partir de complexos e centralidades no território. Rio de Janeiro: Garamond Universitária [Faperj].

SOJA, E. W. (1993). Geografias Pós-Modernas: A Reafirmação do Espaço na Teoria Social Crítica. Rio de Janeiro: Zahar.

SOJA, E. W. (2000). Postmetropolis: Critical Studies of Cities and Regions. Oxford: Blackwell Publishing.

STORPER, M.; WALKEN R. (1989).The Capitalist Imperative: Territory, Technology and Industrial Growth. Oxford: Blackwell Publishing, 